Richardson, A., Gregor, S., \& Heaney, R. (2012). Using decision support to manage the influence of cognitive abilities on share trading performance. Australian J ournal of Management, 37(3), 523-541.

(c) The Author(s) 2012

This is pre-copy-editing, author-produced version of an article accepted for publication in Australian J ournal of Management, following peer review. The definitive published version (see citation above) is located on the abstract page of the publisher, Sage.

This version was made available in the UWA Research Repository the $5^{\text {th }}$ of November 2014, in compliance with the publisher's policies on archiving in institutional repositories.

Use of the article is subject to copyright law. 


\title{
Using decision support to manage the influence of cognitive abilities on share trading performance
}

\author{
Alex Richardson* and Shirley Gregor \\ Research School of Business, The Australian National University, Australia \\ Richard Heaney \\ School of Economics, Finance and Marketing, RMIT University, Australia
}

\begin{abstract}
Online share trading is no longer restricted to expert brokers; there is a diverse population of traders with varying abilities and experience. Decision making in this context can be sub-optimal and risky. This study investigates how performance varies with level of cognitive ability and speed of online trading, and whether a decision aid can overcome traders' disadvantages. The study showed that novice traders with decision support consistently outperformed those without and that the decision aid mitigated the negative effects of higher decision-making speeds and lower cognitive ability. This adds to decision making under time pressure and behavioural finance literature.
\end{abstract}

\section{Keywords}

decision support systems, share trading, cognitive abilities, decision making

Corresponding author: Alex Richardson, School of Accounting and Business IS, Building 21, The Australian National University, Canberra ACT 0200, Australia. Email: alex.richardson@anu.edu.au Tel: +61 26125 9807. Fax: +61 261255005. 


\section{Introduction}

Online share trading has become popular across a diverse population of traders due to an increase in public awareness of online services and the relative ease of gaining access to the share market. Share trading is no longer restricted to expert brokers on trading floors. Instead, online trading systems allow a wide range of traders with varying abilities and experience to participate in buying and selling shares. A number of these traders, apart from having relatively limited exposure to finance and the principles of financial markets, may also be lacking in high-level quantitative skills. Further, online financial markets allow trading to occur rapidly, with the traders making decisions at high speed (Odean, 1999; Barber and Odean, 2002). These conditions in combination would appear to be a recipe for disaster - novice traders with limited knowledge of finance and varying levels of cognitive ability engaged in rapid decision making where the stakes can be high.

While computers were a catalyst for the shift to screen-based electronic trading, they also have the potential to counter negative aspects of this environment. Research and practical applications within industry have shown decision support systems (DSSs) to be beneficial when appropriately designed for a given task (Turban and Aronson, 2001). It is to be expected that DSS could assist traders in an online market, although the literature in this area is sparse, possibly because of the competitive gain that could result from identification of truly effective decision support. 
The aim of this study is to investigate the performance of novice traders in an online share trading environment and whether trading performance varies with level of cognitive skill and speed of trading. It is expected that the increased cognitive load that comes with rapid decision-making is likely to lead to reduced performance (Payne et al., 1993) and that lower cognitive ability is a problem. A further aim is to investigate whether the provision of decision support in this environment will help to overcome problems with high-speed decision-making and limited ability.

The study has significance as it adds to work on the behavioural characteristics of share traders and their performance. The human aspects of share traders are not often considered in "classical" finance studies. For more than forty years, the efficient market hypothesis $(\mathrm{EMH})$ has been a central proposition of finance and defines an efficient financial market as being one which has all the available information reflected in the security prices (Fama, 1970). The EMH relies upon a model of rational professional traders and does not consider the situation of novice traders who are prone to error and an inability to process efficiently all the information cues available to them. Further significance arises as the paper contributes to the literature on decision making under time pressure (Wright, 1974; Payne et al., 1993; Payne et al. 1995).

The paper proceeds as follows. First relevant literature is reviewed, a conceptual model developed and hypotheses advanced. Second the experiment to test the hypotheses is described. The results are then discussed in terms of prior theory. 


\section{Conceptual Background}

The research literatures on DSS, cognitive ability, decision making and share markets are each well-established (Davis and Holt, 1993; Fama, 1970; O’Brien and Srivastava, 1991; Payne et al., 1993; Shefrin, 2000; Turban and Aronson, 2001). However, the understanding of phenomena that occur at the intersections of these fields, as in our problem area of online share trading, are less well understood. To begin, we examine the relevant streams of literature separately: experimental financial markets; decision making and cognitive ability; decision making under time pressure; and decision support systems. We then advance a theoretical model that obtains support across these different fields.

\subsection{Experimental Financial Markets}

The use of electronic trading systems in stock exchanges is comparatively new. Since the 1960s, experiments have been conducted to identify the implications of economic theories of price formation for financial markets (Smith, 1962). As a consequence of this work, the benefits of increased efficiency through electronic auction mechanisms were realised (Cassidy, 1967). It was not until the late 1970s, however, that automated computerised electronic markets became a reality. Studies such as (Wurman et al., 1998) have highlighted the increasing role of electronic auctions in e-commerce, particularly the continuous double auction market variety used in this study. 
Modelling a large share market such as the NYSE or the ASX is not feasible with current technological capabilities; there are simply too many factors to consider when creating an accurate model. Researchers have had success with smaller manual and electronic markets in investigating and determining the effects of certain market mechanisms (Davis and Holt, 1993; Kagel and Roth, 1995). Information aggregation (accumulation of all required information) is one such topic of study and has formed the basis of many experimental studies of share markets (e.g., O'Brien and Srivastava (1991)). The efficient market hypothesis (EMH) postulates that the share price reflects the combined information that all investors possess. The rational expectation (RE) model holds that rational traders will eventually converge to trading steadily at an equilibrium price. The weak form of the RE model states that traders make optimal use of whatever information they have when forming their expectations and that there is no restriction placed upon the information. The strong form however states that traders have access to all available information available and that they make optimal use of it when forming expectations. The RE model has been studied in experimental markets with human traders. There is still room for further work in this field. Some studies show that information is disseminated efficiently (Forsythe et al, 1982; Plott and Sunder, 1982, 1988) but may become less efficient when trader behaviour changes (Gode and Sunder, 1993). 
O’Brien and Srivastava (1991) studied the performance of experienced human traders using a software simulated computerised electronic market with multiple periods and assets. While they found strong evidence against information aggregation, they also found that conventional economic tests were unable to reject the hypothesis of an efficient market (information wise). This work demonstrates the premise that knowledge of individual behaviour in markets is important.

Further indications of behavioural effects concern speed of trading. Brokers are tied into the stock exchange systems and can electronically place market orders with minimal delay. This allows their trader clients to quickly undertake trades via methods such as a website or mobile phone data services. This opportunity for faster trading has been shown to be less than beneficial for some traders (Odean, 1999; Barber and Odean, 2000, 2001, 2002).

\subsection{Decision Making and Cognitive Abilities}

Bounded rationality is where humans are portrayed as partly rational with a tendency for irrational behaviour at times (Simon, 1957). The term 'satisficing' was coined in recognition of the observation that decision makers are only sufficiently rational to meet a particular goal before reverting to other methods of behaviour. By recognising the costs of collecting and processing information, the classical models based on rationality could be made more realistic. Much of this thinking has been applied to economic studies, such as those involving rational agent models (Kahneman, 2003). 
Agents operating under the efficient market hypothesis (Fama, 1970) are assumed to be economically rational even while realistically many have bounded rationality. Behavioural finance, a comparatively young field of study, recognises the importance of models (eg. agent-based) that more accurately reflect the decision-making process. Some share traders will devote an hour each day to online trading in order to satisfy their expectations of a positive financial outcome. However, how that hour is spent is not necessarily optimised for meeting the intended goal. It has been shown that traders who moved from phone-based to online trading decreased trade transaction times but at the cost of reduced investment performance (Barber and Odean, 2002). This shortfall was partially attributed to overconfidence and a failure to recognise the added transactional costs of increased trading frequency even at a lower per trade cost.

Of interest to this study is how individual differences in cognitive ability affect decision-making performance under time pressure. The cognitive abilities of an individual determine his or her capacity to learn new skills, create a repository of knowledge and adapt to new situations (Anstey, 1999). They are also a determinant of the individual's ability to perform routine tasks with speed and accuracy (Salthouse, 1985) and of competency in the workplace (Kolz et al., 1998; Sackett et al., 1998). A study has shown that cognitive ability is a reliable predictor of job performance for almost all employees when completing everyday tasks (Gottfredson, 1997). 
Cognitive ability is often thought of as synonymous with intelligence as assessed through intelligence quotient (IQ) tests. However, the validity of the IQ concept as a single measure of intelligence has been questioned by researchers and more complex models of cognitive ability have been proposed (Anstey, 1999). One comprehensive model is that of Horn $(1982,1985,1987)$, based on work by Cattell $(1941,1971)$. The Cattell-Horn-Carroll (CHC) model provides a hierarchical framework for understanding cognitive abilities. with general mental ability (GMA) at the top of the structure and two broad domains of intellectual functioning - fluid and crystallized abilities — below it. There is an overlap between crystallized and fluid abilities. Both share characteristics in the processes of perceiving relationships, logical reasoning, abstraction, concept formation, problem solving and the like. As the CHC model is well supported in empirical studies, it has been utilised as a base for our work. Of specific interest are three main dimensions: fluid intelligence; crystalline intelligence; and quantitative ability.

The concept of fluid ability is similar to the concept of "raw" intelligence, the innate reasoning ability that people have regardless of the culture into which they are borne. Fluid intelligence develops over time as the brain matures neurologically and starts to diminish in middle to late adulthood. Crystalline intelligence is the general knowledge of facts, strategies and skills that are the result of education, training and experience. Individuals develop these knowledge types during their lifetime and it is often referred 
to as "wisdom" in later years. Individual differences exist between fluid and crystallized intelligence, which mean that some people are better at processing information for tasks than others.

In addition to those two broad domains, there is a subset of other abilities that play a part in human performance by contributing to either fluid or crystallized intelligence: broad visual ability, working memory, long-term memory, cognitive speed and quantitative knowledge. Quantitative knowledge is of particular interest due to the financial nature of share trading and has been harder to distinguish from fluid and crystallized intelligence in the sense that it depends on both stored knowledge and immediate awareness. It can be thought of as the factor of cognitive intelligence that refers to thinking with numerical materials like basic mathematical operations and financial reasoning (eg. taxation and interest rate calculations).

This study continues work which showed that crystalline ability significantly influenced financial performance, but that fluid abilities did not (Richardson et al, 2004). The conclusion was that that developed knowledge was more beneficial in this specialised field than innate reasoning ability. In addition to crystalline ability, quantitative knowledge, a combination of stored knowledge, immediate awareness and the ability to "think" in a mathematical way, is also expected to be a factor in determining performance at share trading.

The above arguments result in the following two hypotheses: 


\section{H1a: A higher level of crystallized ability will lead to higher performance in financial trading by novice traders. \\ H1b: A higher level of quantitative knowledge will lead to higher performance in financial trading by novice traders.}

\subsection{Decision Making under Time Pressure}

The decision-making process is context dependent and relies on factors both internal (e.g., time pressure) and external (e.g., time constraints) to the decision-maker. Reduced performance is expected when there are time pressure and constraints because a decision-maker is likely to engage in non-compensatory rather than compensatory decision-making. Compensatory processes involve all available information in the decision process whereas non-compensatory processes involve only a portion of the total available information (Payne et al, 1993). A study found that compensatory processes may lead to decisions of higher quality but at the cost of increased cognitive load (Hogarth, 1987).

To clarify the terminology used, it is important to note that the use of the terms 'time constraint ' and 'time pressure' are at times used interchangeably in the literature (Svenson and Maule, 1993). For the purposes of this study, the two concepts are distinguished (Ordonez and Benson, 1997). Time constraint: A deadline or time restriction imposed upon a task when the decision-maker has a limited amount of time in which to make the decision. This constraint is often fixed to a particular value for 
experimental purposes, either arbitrarily or based on previous findings. Time pressure: The stress induced as a result of a time constraint on a human decision-maker. It is possible to have a time constraint but not time pressure if the decision-maker can arrive at a decision within the time constraint period.

Numerous empirical studies have concluded that time pressure has a significant impact on decision strategy (Wright, 1974; Ben Zur and Breznitz, 1981; Wurman et al., 1998) and effectiveness (Peters and O’Conner, 1980; Peters et al., 1984). It has been found that decision-makers adopt simplified strategies when time pressure is high and place greater emphasis on negative information for decision alternatives (Wright, 1974; Zakay and Wooler, 1984). It was also found the experimental participants focused more upon negative information and preferred less risky alternatives under time pressure (Ben Zur and Breznitz , 1981). These researchers found that as time pressure increased, decision quality decreased. A reduction in decision quality was also observed (Payne et al, 1993; Payne et al., 1995). Other effects considered to be a result of time pressure are a move towards less extreme judgements (Kaplan et al., 1993) and a reduction in risk propensity (Ben Zur and Breznitz, 1981). Time constraints, rather than time pressure, have also been found to have a negative influence on decision-making by (Wallsten and Barton, 1982; Rothstein, 1986; Kerstholt, 1994).

In the share trading environment, there is a limited amount of time for decisionmaking. A trader who chooses to trade more often decreases the time available for each 
decision. The Financial Trading System (FTS) used in this study provides an interface and trading environment similar to that of real-life systems, such as the Stock Exchange Automated Trading System (SEATS) used at the Australian Stock Exchange. Traders trade more actively when using online systems than when using the phone (Barber and Odean, 2002). In this case, the time constraint is self-imposed rather than imposed by external conditions. It is expected that the more trading actions performed by each individual within a time period, the worse his or her performance, due to increased time pressure and a shift towards non-compensatory decision processes. This effect will be more marked with novice traders who have less experience dealing with the decision making processes under time pressure. This reasoning leads to the following hypothesis:

\section{H2: Higher decision-making speed will lead to lower performance in financial trading by novice traders.}

\subsection{Decision Support Systems}

A computerised DSS offers many support features, including the ability to manipulate a large amount of information, produce reports in a flexible task-specific format, access different customisable analysis methods, support different decision-making frequencies and provide for a range of optimisation, satisficing and heuristic approaches.

The few studies investigating the effects of decision support on share trading are limited to the use of graphs and indicators showing historical information (e.g., volume weighted average prices and market indicators). For example, a business simulation 
involving investment decisions and uncertain economic conditions (Sharda et al., 1988). The study showed (as expected) that decision-makers with access to a DSS made significantly more effective decisions than their counterparts who lacked a DSS. Interestingly, the DSS users took longer to make their decisions. After repeated usage, however, the decision-making times converged.

A decision support tool should provide for higher decision quality by a novice trader for the same (or lower) level of cognitive effort. Novice traders using a decision aid that supports the fundamentals of share pricing will have a financial performance benefit over novice traders without similar support. Memory intensive calculations can be simplified and thus allow cognitive resources to be allocated to other tasks. A correctly designed decision aid will enhance the inherent cognitive abilities of a decision-maker. This reasoning leads to another hypothesis:

\section{H3: The use of a decision aid by novice traders will lead to higher performance in financial trading.}

Although the availability of decision support is expected to result in improved financial performance for all novice traders who use it, it is expected that it will be most beneficial to novice traders with limited cognitive abilities (i.e., crystallized abilities and quantitative knowledge) for reasons outlined earlier. This reasoning results in the following hypotheses: 
H4a: A decision aid can mitigate the detrimental effects of lower crystallized ability on financial trading performance by novice traders.

H4b: A decision aid can mitigate the detrimental effects of lower quantitative knowledge on financial trading performance by novice traders.

Similarly, it is expected that decision support can enable novice traders to trade more quickly without suffering the negative effects of cognitive overload and resultant errors or lapses in judgement. This argument is reflected in the following hypothesis:

H5: A decision aid can mitigate the detrimental effects of higher trading speed on financial trading performance by novice traders.

Figure 1 shows the research model and hypotheses that represent the arguments advanced. 
Figure 1. Research Model

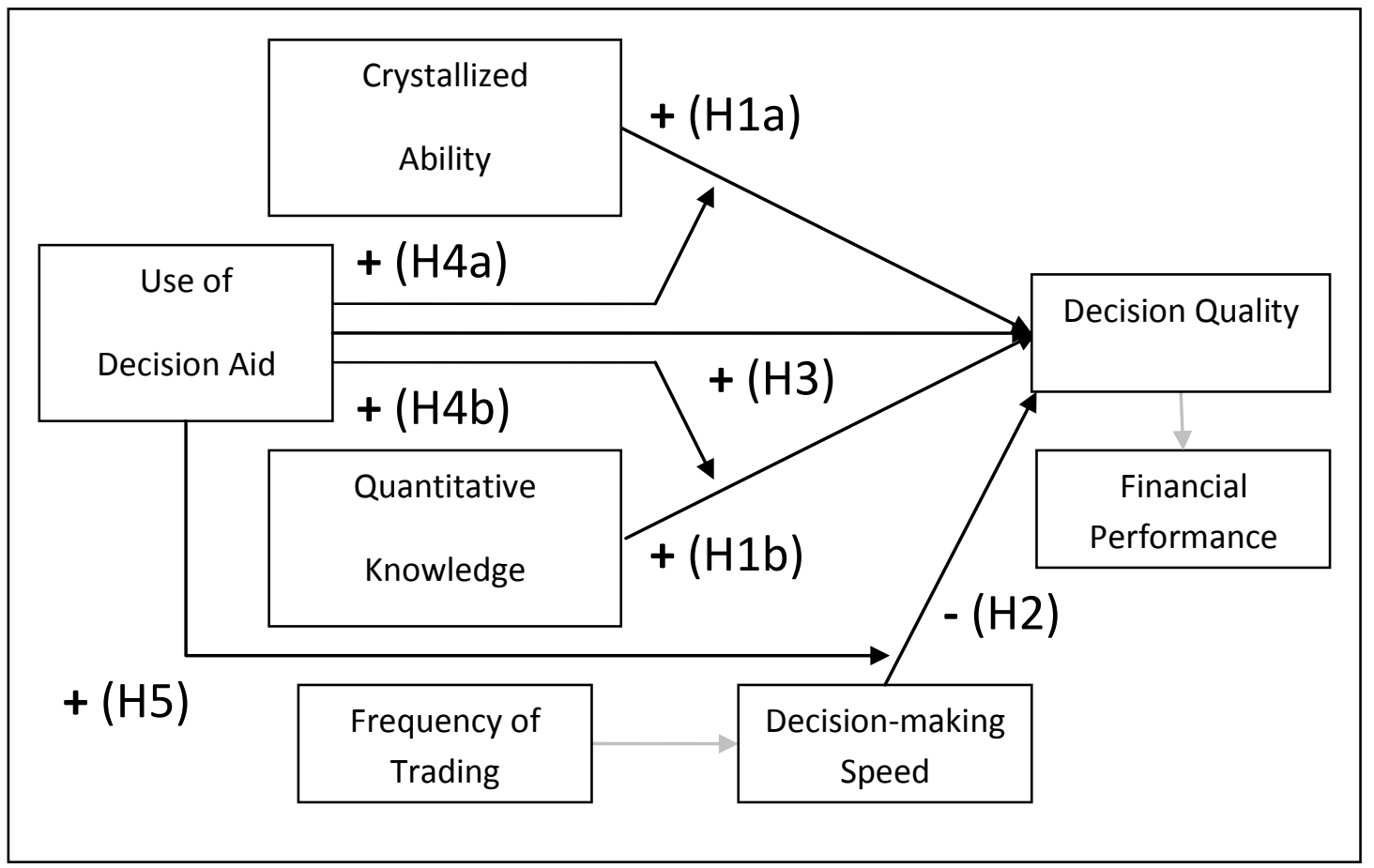

\section{The Study}

\subsection{Participants}

The participants were 30 volunteers from a class of approximately 400 students in a first year university finance course that taught financial market fundamentals. This sample consisted of 9 females and 21 males. The median age was 19 years. Approximately 47 per cent of the participants indicated that English was not their first language but had met a minimum TESOL English proficiency standard (Teachers of English to Speakers of Other Languages accreditation, or an equivalent for academic English, is a requirement of enrolment). Finance students are regarded as being representative of 
novice share traders, as they have some knowledge and experience with share trading, but have not reached an expert stage, compared with professional traders.

\subsection{Procedure}

The experiment had two parts, an initial training session and the experiment proper. In the training session, each participant first completed an e-bilities ${ }^{\circledR}$ test to measure his or her cognitive abilities. This test took approximately 45 minutes. The participants were then shown how to use the Financial Trading System (FTS). They then participated in four trials of the system under conditions similar to those of the experiment proper. Each trial consisted of two five-minute periods of trading. This part of the training session took approximately one hour and formed part of an extra-curricular activity to strengthen the student's understanding of financial concepts completed in their coursework.

For the main experiment, the participants were allocated randomly to two groups. One group was provided with a decision aid (16 participants) and the other group did not receive an aid (14 participants). This experimental session took two hours and involved six trials, each with two five-minute periods of trading.

\subsection{Materials}

A Java-based testing suite called e-bilities® (http://www.ebilities.com), developed by the Lewis Cadman Group, was used to test cognitive abilities. The customised ebilities ${ }^{\circledR}$ test suite used collected demographics (name, occupation, education, English 
ability, age, gender and ethnicity) and cognitive measures (Swaps ${ }^{\circledR}$, TripletsTM, Series, Word and Quantitative Knowledge).

The real-time trading software package used was the Financial Trading System (FTS), which was developed by OS Financial Trading System and is described in (O’Brien and Srivastava, 1991). It is used to create experimental financial trading markets. The system provides participants with trading experience in a simple market environment. The "market efficiency" game used in this study is the simplest of a comprehensive set of market scnarios supplied by OS Financial Trading Systems.

Figure 2 provides a copy of the FTS trading screen. The key features of the interface are apparent in this screen dump including the facility to enter bid and ask price and quantity as well as disclosure of other important information about the game such as the current bid and ask prices and the current position of the participant in each of the two stocks, $\mathrm{ABC}$ and CRA. The two securities may pay dividends at the end of period 1 and period 2 .

In the original FTS system, the central white rectangle in the screen would normally contains the participant's private information about the dividend that a share would pay. For this experiment, the package was modified so that the private information was displayed by an Excel spreadsheet. The no-aid group of novice traders received only the original basic private information (Figure 3 and Figure 4) which is a tabular representation of the private information normally displayed in the centre text box of the 
trading screen. The other group of traders received additional information, which was an interpretation of the basic information to give them expected values and a range of possible values (Figure 5 and Figure 6).

Critics of information systems have argued that, in aiming to present information that a user requires, systems can provide misinformation and cognitive overload (Ackoff, 1967). In this experiment, considerable effort was devoted to designing an aid that had an appropriate format and provided information in a useful form.

Tabular and graphical information presentation formats have been shown to be more useful for displaying information for problem solving than raw data (Chervany and Dickson, 1974; Remus, 1984; Benbasat and Dexter, 1985). Given the nature of the information needed to be communicated to the novice trader, a tabular format with both row and column lines was selected as the most suitable means of increasing readability performance (Wu and Yuan, 2003). Figure 5 and Figure 6 show a static representation for Period 1 and 2 respectively of the information displayed by the decision aid, which had the intention of providing highly visible and unbiased information. Colours (other than black text on a white background) were used for decision aid text and table cells to promote the quicker identification of important information and enhance readability by distinguishing among information items. 
Figure 2. Copy of the trading screen in the FTS

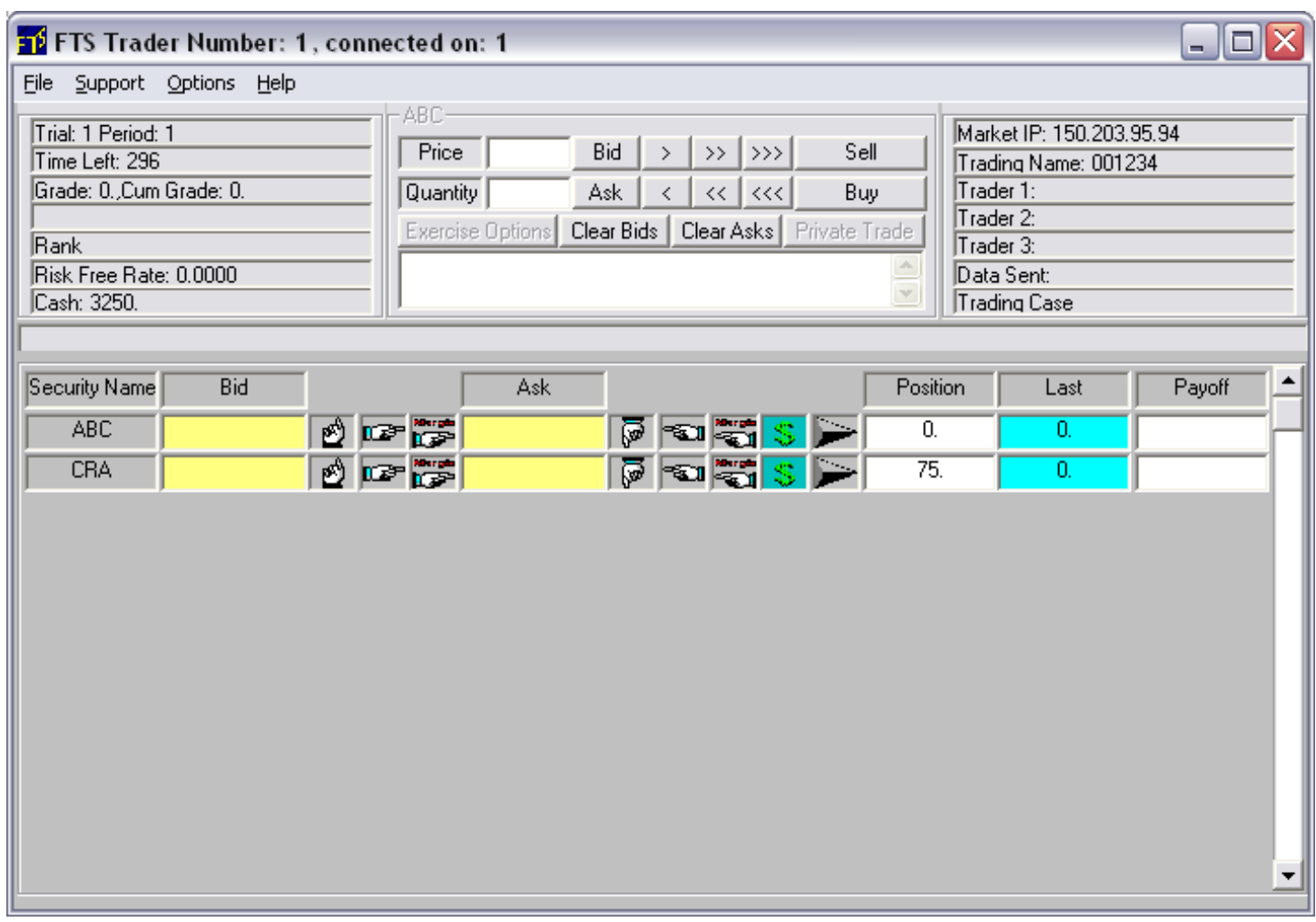

Figure 3. Example of Period 1 Private Information (without Decision Aid)

\begin{tabular}{|r|c|}
\hline ABC private information is: & \\
\hline Period 1: Not & $\mathbf{X}$ \\
\hline Period 2: Not & $\mathbf{X}$ \\
\hline
\end{tabular}

\begin{tabular}{|r|c|}
\hline CRA private information is: & \\
\hline Period 1: Not & w \\
\hline Period 2: Not & w \\
\hline
\end{tabular}


Figure 4. Example of Period 2 Private Information (without Decision Aid)

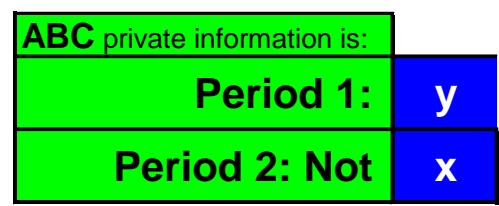

\begin{tabular}{|r|c|}
\hline CRA private information is: & \\
\hline Period 1: & $\mathbf{z}$ \\
\hline Period 2: Not & $\mathbf{w}$ \\
\hline
\end{tabular}

Figure 5. Example of Period 1 Private Information (with Decision Aid)
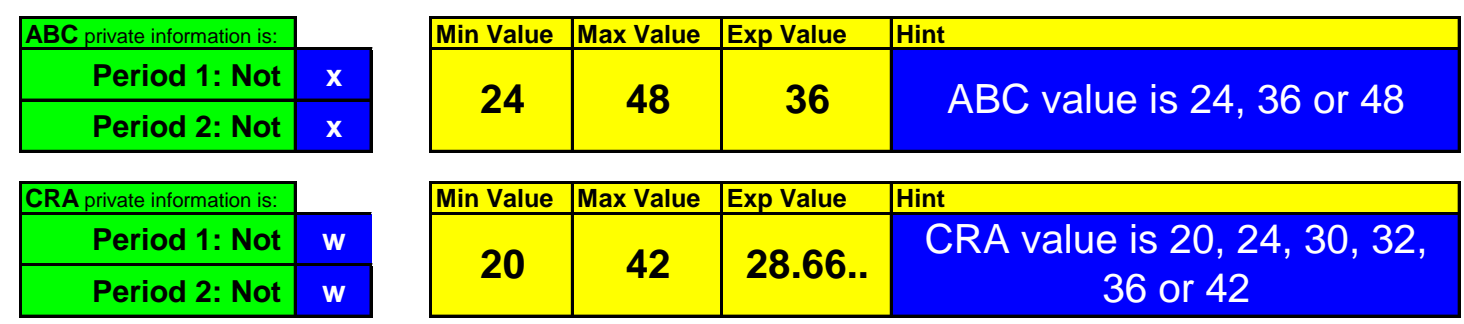

Figure 6. Example of Period 2 Private Information (with Decision Aid)

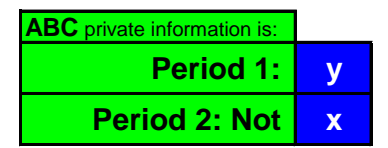

\begin{tabular}{|c|c|c|c|}
\hline Min Value & Max Value & Exp Value & Hint \\
\hline 12 & 24 & 18 & ABC value is 12 or 24 \\
\hline Min Value & Max Value & Exp Value & Hint \\
\hline 8 & 18 & 12.66.. & CRA value is 8,12 or 18 \\
\hline
\end{tabular}

\subsection{Design}

The experiment focussed on the effect of introducing a decision aid to the trading

environment. The primary dependent variable in a regression analysis was overall

financial performance (FINP_TOT). It was calculated from the earnings (grade cash) 
generated by the participants' trades over the length of the entire experiment (6 trials). The control covariates were gender (GENDER) and whether English was the participant's first language (ENGLISH).

The e-bilities ${ }^{\circledR}$ measures used were the accuracy performance components (percentage of correct responses) of the measures for crystallized ability and quantitative knowledge. These two variables, CRYST and QK, were used as the cognitive independent variables. A further independent variable was the number of trading actions, which was measured for all six trials (NUM_ACTS_TOT).

The treatment group was denoted as AID_USED. Three interaction variables (AID_USED*CRYST, AID_USED*QK and AID_USED*NUM_ACTS) were created to address the research hypotheses.

Table 1 summarises the variables used in the analysis. 
Table 1. Experiment Variables

\begin{tabular}{|c|c|c|}
\hline Variable Type & Variable Name & Description \\
\hline Dependent & FINP_TOT & $\begin{array}{l}\text { Financial performance [accumulated grade cash } \\
\text { profit/loss resulting from trading] }\end{array}$ \\
\hline Control & $\begin{array}{l}\text { GENDER } \\
\text { ENGLISH }\end{array}$ & Demographics [collected via questionnaire] \\
\hline \multirow[t]{4}{*}{ Independent } & CRYST & $\begin{array}{l}\text { Crystallized ability [collected using e-bilities test } \\
\text { suite] }\end{array}$ \\
\hline & QK & $\begin{array}{l}\text { Quantitative knowledge [collected using e-bilities } \\
\text { test suite] }\end{array}$ \\
\hline & NUM_ACTS_TOT & $\begin{array}{l}\text { Number of trading actions [recorded by market } \\
\text { simulation server software] }\end{array}$ \\
\hline & AID_USED & Decision aid availability \\
\hline \multirow[t]{3}{*}{ Interaction terms } & $\begin{array}{l}\text { AID_USED * } \\
\text { CRYST }\end{array}$ & Interaction effect with Crystallized ability \\
\hline & AID_USED * QK & Interaction effect with Quantitative knowledge \\
\hline & $\begin{array}{l}\text { AID_USED * } \\
\text { NUM_ACTS_TOT }\end{array}$ & Interaction effect with number of trading actions \\
\hline
\end{tabular}

\section{Results}

The data was screened to test whether the assumptions required for the performance of a regression analysis were met (Tabachnick and Fidell, 2001). Some transformations were applied as distribution of some variables was not normal. Table 2 shows the descriptive statistics before and after transformation ( $T_{-}$prefix) for normalisation had been performed. 
Table 2. Descriptive Statistics (normalisation transformations prefixed with $\mathrm{T}_{-}$)

\begin{tabular}{lcrrrrrrrr}
\hline & & & & & \multicolumn{3}{c}{ Skewness } & \multicolumn{2}{c}{ Kurtosis } \\
& N & \multicolumn{1}{c}{ Min } & \multicolumn{1}{c}{ Max } & \multicolumn{1}{c}{ Mean } & \multicolumn{1}{c}{ S.D. } & \multicolumn{1}{c}{ Stat } & \multicolumn{1}{c}{ S.E. } & \multicolumn{1}{c}{ Stat } & \multicolumn{1}{c}{ S.E. } \\
\hline FINP_TOT & 30 & -7070.15 & 7708.34 & 3.2630 & 2411.64254 & -.560 & .427 & 7.184 & .833 \\
T_FINP_TOT & 30 & -2.0403 & 2.0403 & 0.0000 & .97279 & .000 & .427 & -.318 & .833 \\
CRYST & 30 & .32 & .86 & .6605 & .12688 & -1.258 & .427 & 1.513 & .833 \\
T_CRYST & 30 & .39 & .83 & .5827 & .10168 & .787 & .427 & .820 & .833 \\
QK & 30 & .17 & .92 & .6370 & .17765 & -.575 & .427 & .222 & .833 \\
NUM_ACTS_TOT & 30 & 58.00 & 2373.00 & 614.6333 & 526.98508 & 2.211 & .427 & 5.328 & .833 \\
T_NUM_ACTS_TOT & 30 & 1.76 & 3.38 & 2.6618 & .34870 & -.385 & .427 & 1.092 & .833 \\
Valid N (listwise) & 30 & & & & & & & & \\
\hline
\end{tabular}

A standard linear regression model in SPSS v15 was used to test the experimental hypotheses. The endogenous dependent variable is overall financial performance. There were four main exogenous independent variables: crystallized ability (reflect and square root), quantitative knowledge, total trading actions (log) and aid available for use. In addition, there were also the interaction terms of aid usage with the other three variables. The control variables of confidence, understanding, English ability and gender were found not to correlate with financial performance and were omitted from analysis.

An a priori test was run with $\mathrm{G}^{*}$ Power (Faul et al., 2007) to compute the required sample size. In order to find a statistically significant relationship in the regression for a large effect $\left(f^{2}=.35\right)$ with seven independent variables, a sample size of at least 49 is required to achieve power of $.80(p=.05)$. It is acknowledged that the analysis is one of 
low power. However, limits on server processing capacity in an experimental market simulation meant that the use of a larger number of participants was not feasible. Sensitivity analysis calculated using $\mathrm{G}^{*}$ Power found an effect size $\left(f^{2}\right)$ of 0.647 is required with a sample size of 30 .

Table 3 shows the regression results, including the correlations among the variables, the unstandardised regression coefficients $(B)$ and intercept, the standardised regression coefficients $(\beta)$, the semi-partial correlations $\left(s r_{i}^{2}\right)$ and $R^{2}$, and the adjusted $R^{2}$. The regression $R$ was significantly different from zero, $F(7,22)=10.157, p<.001$. For the six regression coefficients that differed significantly from zero, 95 per cent confidence limits were calculated. The confidence limits for (reflect and square root of) crystallized cognitive abilities were -6.364 to 0.264 , (log of) number of trading actions were -2.400 to -0.476 and aid available for use were -4.883 to -4.624 .

Six of the independent variables contributed significantly to explaining financial performance as ranked: (reflect and square root) crystallized ability $\left(s r_{i}^{2}=.039\right)$, number of actions $\left(s r_{i}^{2}=.103\right)$, aid available for use $\left(s r_{i}^{2}=.167\right)$, (reflect and square root $)$ crystallized ability $*$ aid available for use $\left(s r_{i}^{2}=.036\right)$, quantitative knowledge $*$ aid available for use $\left(s r_{i}^{2}=.070\right)$ and number of actions $*$ aid available for use $\left(s r_{i}^{2}=\right.$ .129). The seven independent variables combined contributed another .218 in shared variability. Altogether, over 76 per cent (69\% adjusted) of the variability in financial performance was predicted by scores on these seven independent variables. 
Although the correlation between quantitative knowledge and ranked financial performance was -0.342 , QK did not significantly contribute to the regression. Post hoc evaluation of the correlation revealed that it was not significantly different from zero, $F(7,22)=0.416$ 
Table 3. Standard Multiple Regression of Cognitive Abilities, Number of Trading Actions and Aid Usage on Financial Performance

\begin{tabular}{|c|c|c|c|c|c|c|c|c|c|c|c|}
\hline & $\begin{array}{c}\text { T_ }_{-} \\
\text {FINP_TO } \\
\text { T } \\
\text { (DV) }\end{array}$ & T_CRYST & QK & $\begin{array}{l}\text { T_NUM_ } \\
\text { ACTS_T } \\
\text { OT }\end{array}$ & AID_USED & $\begin{array}{l}\text { AID_USED* } \\
\text { T_CRYST }\end{array}$ & $\underset{{ }^{*} \mathbf{Q K K}}{\text { AID_USED }}$ & $\begin{array}{l}\text { AID_USED* } \\
\text { T_NUM_- } \\
\text { ACTS_TOT }\end{array}$ & $B$ & $\beta$ & $\begin{array}{c}s r^{2} \\
\text { (unique) }\end{array}$ \\
\hline \multicolumn{12}{|l|}{ Variables } \\
\hline T_CRYST & $-.274^{\wedge}$ & & & & & & & & $-3.050^{\wedge}$ & -.319 & .039 \\
\hline QK & $.342 *$ & -.139 & & & & & & & -.477 & -.087 & \\
\hline $\begin{array}{l}\text { T_NUM_ } \\
\text { ACTS_TOT }\end{array}$ & -.173 & $-.241^{\wedge}$ & .160 & & & & & & $-1.438^{* *}$ & -.515 & .103 \\
\hline AID_USED & $.582 * * *$ & .008 & .114 & -.223 & & & & & $-9.753 * * *$ & -5.087 & .167 \\
\hline $\begin{array}{l}\text { AID_USED* } \\
\text { T_CRYST }\end{array}$ & $.515^{* *}$ & .168 & .011 & $-.264^{\wedge}$ & $.973^{* * *}$ & & & & $4.327^{\wedge}$ & 1.354 & .036 \\
\hline $\begin{array}{l}\text { AID_USED* } \\
\text { QK }\end{array}$ & $.726^{* * *}$ & -.138 & $.441 * *$ & -.157 & $.914 * * *$ & $.841 * * *$ & & & $3.734^{*}$ & 1.397 & 070 \\
\hline $\begin{array}{l}\text { AID_USED* } \\
\text { T_NUM_- } \\
\text { ACTS_TOT }\end{array}$ & $.617 * * *$ & -.028 & .137 & -.093 & $.983 * * *$ & $.944 * * *$ & $.911 * * *$ & & $2.200 * *$ & 3.023 & .129 \\
\hline Means & 0.000 & .583 & .637 & 2.662 & .53 & .311 & .350 & 1.381 & & & \\
\hline $\begin{array}{l}\text { Standard } \\
\text { deviations }\end{array}$ & 0.973 & .102 & .178 & .349 & .507 & .304 & .364 & 1.337 & & & \\
\hline \multicolumn{12}{|l|}{ Intercept $=5.418$} \\
\hline \multicolumn{12}{|l|}{$\mathrm{R}^{2}=.764^{\mathrm{a}}$} \\
\hline \multicolumn{12}{|c|}{ Adjusted $\mathrm{R}^{2}=.688$} \\
\hline
\end{tabular}




\section{Discussion}

The purpose of this experiment was to investigate the relationships between cognitive ability, decision-making speed and financial performance when a decision aid was provided to one of the two subject groups. It was found that crystallized ability, quantitative knowledge and number of trading actions influenced financial performance when the novice trader had a decision aid available for use. Other demographics, including gender, age, English ability and prior financial trading experiences were examined as potential covariates, but showed no significant relationship to trading performance.

Hypothesis \#1a was supported as crystallized ability was related to performance. Hypothesis \#1b was not supported as quantitative knowledge was not related to performance. Hypothesis \#2 was supported. The findings show that the number of trading actions was significantly negatively related to financial performance. All three of these hypotheses had significant interaction effects also.

Hypothesis \#3 was supported as the performance for the group with the decision aid was significantly higher, as found in the results of the t-test of difference between the financial performance means for the two experimental test groups $(p<.001)$. Non-aid users had a mean of -.594 with a 95 per cent confidence interval between 0.933 and -2.122 . The aid users had a mean of .520 with a 95 per cent confidence interval of -1.159 and 2.120 respectively (This is based on a normalised rank transformation with 2.0403 representing the highest financial performance and -2.0403 the lowest). The regression analysis showed aid usage to have a significant effect on financial performance $(p<.001)$. However, with the expected interaction effects also significant, the effect of aid usage alone does not provide a full explanation.

Hypothesis \#4a was supported with the interaction effect between the presence of the aid and crystallized ability being significant $(p=.079$ ) (see Table 4 and Figure 7). Those novice 
traders with a higher level of crystallized ability performed better than those with a lower ability in both the aid and no-aid groups. The slopes of the lines in Figure 7 indicate that the difference in performance of low crystallized and high crystallized traders is not as great in the aid condition as in the no-aid condition. The high-crystallized-ability traders with decision support performed better than low-crystallized-ability traders. Without the aid, the difference between low and high ability was greater. Using the aid meant the difference in ability was 'smoothed' out.

Table 4. Mean Financial Performance (T_FINP_TOT) in each group

\begin{tabular}{ccc}
\hline & $\begin{array}{c}\text { Low Crystallized } \\
\text { Ability group }\end{array}$ & $\begin{array}{c}\text { High Crystallized } \\
\text { Ability group }\end{array}$ \\
\hline No aid & -0.71 & -0.48 \\
With aid & 0.46 & 0.58 \\
\hline
\end{tabular}

Figure 7. Plot of Financial Performance (T_FINP_TOT) values

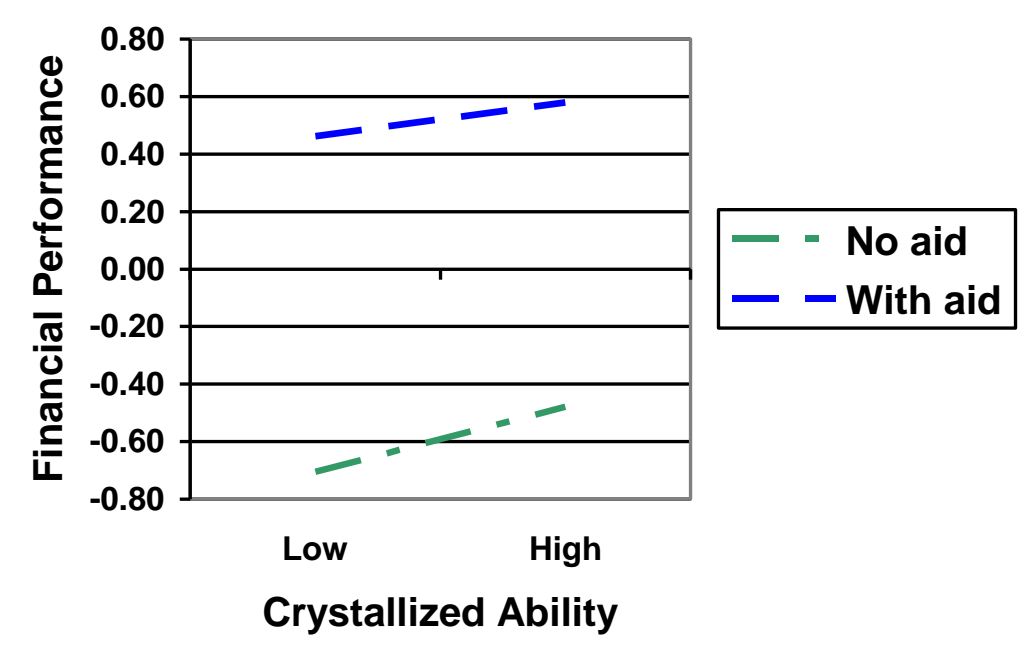

Hypothesis \#4b was supported with the interaction effect between the presence of the aid and quantitative knowledge being significant $(p=.018)$ (see Table 5 and Figure 8). Users with the aid outperformed novice traders with similar quantitative ability who did not have the aid. It is interesting to note the direction of the 'no aid' slope. It shows that novice traders without the aid performed worse as the level of discrete cognitive ability increased. It can 
also be seen that irrespective of whether a novice trader had an aid, traders with a lower cognitive ability had similar mean performance values.

One interpretation of these findings is that the aid not only reduces the burden of part of the decision-making process but may also limit the damage caused by a disparity in a trader's actual ability and their perceived ability. Novice traders with the aid and high quantitative knowledge could maximise the benefits of combining the aid with their quantitative skill to increase their performance. Novice traders with similar high levels of quantitative ability but without the aid had to rely upon their own mental models (which were possibly overcomplicated and may not have been truly representative of what was actually happening in the market). They may also have demonstrated over-confidence.

Table 5. Mean Financial Performance (T_FINP_TOT) in each group

\begin{tabular}{ccc}
\hline & $\begin{array}{c}\text { Low Quantitative } \\
\text { Knowledge group }\end{array}$ & $\begin{array}{c}\text { High Quantitative } \\
\text { Knowledge group }\end{array}$ \\
\hline No aid & -0.28 & -1.02 \\
With aid & 0.04 & 1.00 \\
\hline
\end{tabular}

Figure 8. Plot of Financial Performance (T_FINP_TOT) values

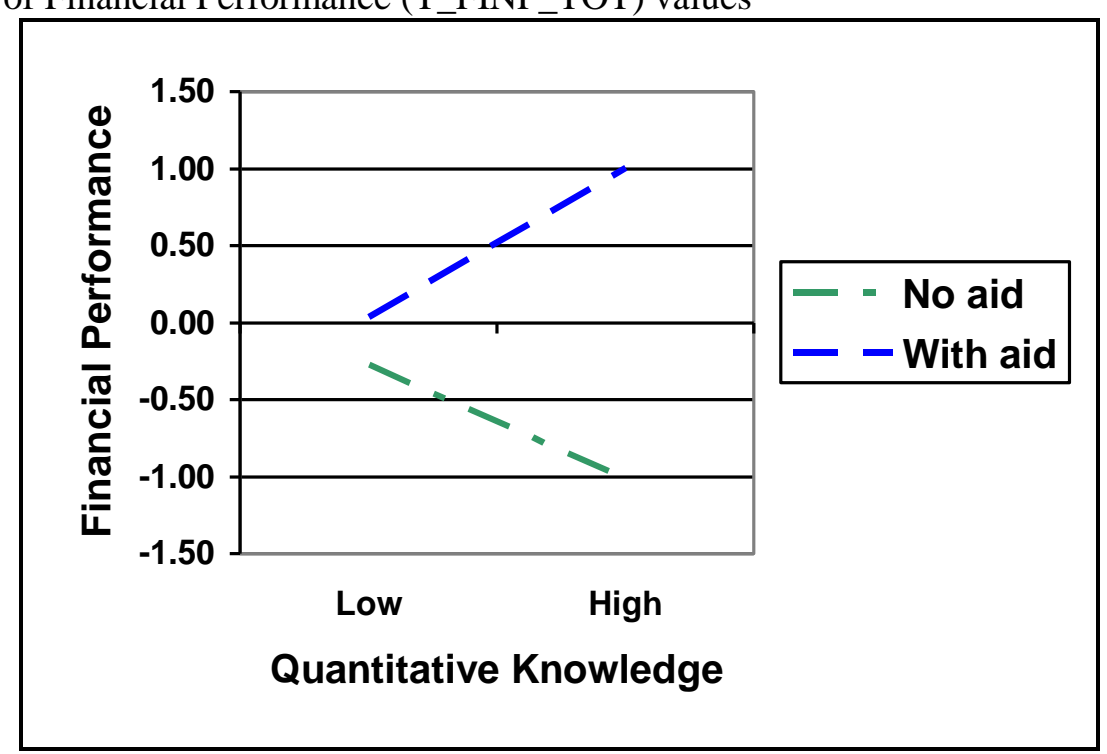

The main effect of the number of trading actions was significantly related to decreased performance $(p=.005)$. However, the interaction effects also need to be considered. 
Hypothesis \#5 was supported with the interaction effect between the presence of the aid and trading speed being significant $(p=.002)$ (see Table 6 and Figure 9). The novice traders who lacked the aid and undertook high levels of trading performed worse than novice traders with lower levels of trading. This supports the findings of Barber and Odean (2002) that 'the slow do not die first'. In addition to this, novice traders with the decision aid and higher levels of trading action performed better than the 'slower' novice traders. It appears that the aid provides a performance advantage that outweighs the ill-effects of high trading speed. Novice traders with more trading actions and decision support having a corresponding higher level of positive performance trades (i.e., making higher quality decisions resulting in 'good trades'). Thus, Hypothesis 5 is supported.

Table 6. Mean Financial Performance (T_FINP_TOT) in each group

\begin{tabular}{ccc}
\hline & $\begin{array}{c}\text { Low Number of Trading } \\
\text { Actions group }\end{array}$ & $\begin{array}{c}\text { High Number of Trading } \\
\text { Actions group }\end{array}$ \\
\hline No aid & -0.34 & -0.84 \\
With aid & 0.21 & 0.83 \\
\hline
\end{tabular}

Figure 9. Plot of Financial Performance (T_FINP_TOT) values

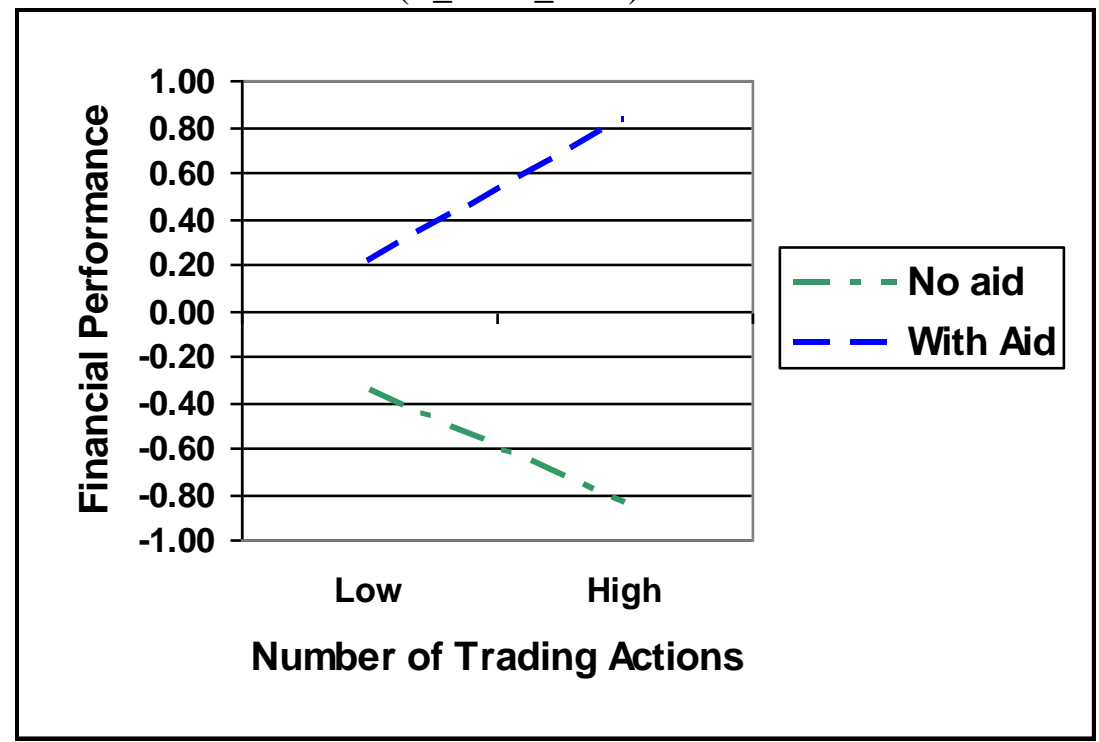




\section{Conclusions}

When considering cognitive abilities overall, crystallized ability had a significant effect on performance, while quantitative knowledge did not. The number of trading actions was also significant. However, with the existence of significant interaction effects in the model, interpreting the main effect alone was not advised. Instead, the interaction effects of aid usage with each of the main effects gave a much clearer picture of novice trader characteristics.

The aid use main effect by itself was significant in the regression analysis. In all conditions, novice traders who had the decision aid performed better than those without it. Decision aid users with higher cognitive abilities or higher decision-making speed also had higher financial performance. All of these findings were as hypothesised.

There were interesting results for novice traders who did not have the aid. As expected, they performed worse the more they traded. Contrary to predictions, novice traders with no aid and higher levels of quantitative abilities performed worse than novice traders with lower abilities. That higher quantitative abilities was actually a hindrance for financial performance deserves further research. It is suggested that the decision aid acted as a mental outer boundary for the decision-making model; novice traders lacking the aid and having more cognitive abilities attempted more than they could handle in the decision-making process.

Novice traders with lower cognitive ability exerted less cognitive effort and most likely focused on a few pieces of information. This created a smaller bounded decision model than the one used by their fellow non-aid novice traders who had higher cognitive abilities.

\subsection{Theoretical Implications}

These findings have several theoretical implications for novice traders. In particular, they strengthen the case for including more psychological decision-making research into behavioural finance. The statistical analyses show that certain aspects of cognitive ability are 
important in online trading. This is the first known study investigating such an issue and it is clear that there is need for further studies to clarify these findings.

Barber and Odean (2002) argued that further research needed to be undertaken into the proposition that experienced traders (compared to the novices in this study) who trade more often perform worse due to overconfidence. They also proposed that traders ignored transaction costs (numerous small trades carry excessive transaction cost overheads). While this study had zero transaction costs, the trading behaviour exhibited in the experiment partially supports those findings. Without support from a decision aid, high levels of trading actions resulted in either highly positive (believed to be quality decision-making) or highly negative trading performance (believed to be inferior decision-making).

This significant relationship between aid usage, trading actions, cognitive abilities and financial performance supports the well-understood stance that maintaining quality decisionmaking at high speed is something to strive for. The influence of other external factors, such as time pressure and stress, may also be mitigated by the use of a decision aid.

\subsection{Policy and Practice Implications}

This research has several practical implications. It demonstrates the need for financial advisors to understand the cognitive abilities of a novice trader (and potentially also experienced traders). Professional day traders are often profiled for certain personality traits that firms consider more attractive for the tasks required. Recreational investors are rarely subject to such scrutiny. Understanding what parts of cognitive ability need more support than others will increase trading efficiency and make trading goals more obtainable, be it lowering risk or increasing returns.

Share markets are risky at the best of times and the level of risk is indicative of potential returns. In general, the higher the returns, the higher the risk. If decision aids can mitigate some of the perceived risk and increase trading activity, small investor portfolios for novice 
traders may progress beyond investment in 'buy and hold' dividend bearing blue chip securities.

\subsection{Limitations}

Students from a large first year finance course were invited to participate in the experiment.

While this may result in a bias due to 'better' students being more likely to volunteer, students signed up for a variety of reasons (e.g., financial incentive, new experience, relevance to studies, social interaction and peer pressure). These reasons also reflect motivating factors for real-life traders in their decision to trade shares on the Internet (O'Brien and Srivastava, 1991). The participants in the experiments were academically competent, consistent with their meeting the relatively high university entrance requirements. Finance students were the focus because it was determined that they would be more representative of those likely to take up share trading. They were also more likely to have the experience to understand the task required of them-share trading in an experimental share market. Experimental finance studies also typically use undergraduate students to represent novice traders. The use of undergraduate finance students in this study allowed them to gain a better understanding of the coursework concepts they were introduced to a few weeks prior to the period in which the experiments were held.

With the study focussing primarily on the effect of cognitive abilities and decision support on financial performance, it was deemed that a computer lab setting was preferable to the participants being situated in a more general office/home environment. Though the market software could theoretically work over the Internet, the organisational logistics and loss of control over inappropriate participant behaviour that this approach would evoke made this unfeasible. 


\subsection{Future research}

The thought processes of the human mind involve much more than what has been investigated in this study. Four cognitive tests available in e-bilities ${ }^{\circledR}$ were used in this study. While these measures were carefully chosen, other aspects of cognitive ability exist that may influence financial performance in a trading environment.

The realism of the experimental market also needs further development. This study used short periods where trading behaviour was compressed and with novice traders as participants. A replication performed over a significantly longer time, where securities are traded in a market that more realistically mirrors an actual exchange (like the ASX or NYSE) is encouraged, with both novice and experienced traders. The findings would be enhanced if a larger sample size were used and a more extensive analysis were undertaken with respect to the decision support capability of trading tools.

\subsection{Summary}

This research has contributed to knowledge in the following ways. First, it has identified that a person's cognitive ability influences his or her trading performance. This point has been assumed but never demonstrated prior to this study. In particular, this research has shown that crystallized intelligence has the greatest influence on trading performance and that quantitative knowledge is also influential in certain circumstances.

Second, this research has shown that the speed of decision-making reliably predicts a trader's financial performance. Unaided traders performed worse on average the more they traded. While this may be attributed to overconfidence, as Barber and Odean (2002) would suggest, it does reflect the negative consequences of excessive speculative trading (even more so if these experimental markets had transaction costs enabled). While the setting used in this study is substantially different, the experiment results do show that higher decision quality rather than lower trading quantity is more closely linked to positive performance. This 
furthers the findings of Barber and Odean (2002) by showing that frequent quality trades (due to decision support) benefit financial performance (as one would expect).

Finally, this research has shown that decision support plays a significant role in trading performance. Users of the aid performed more strongly (on average) and those with both higher cognitive abilities and increased levels of trading further improved their performance.

\section{Acknowledgements}

This work was supported by the Australian Research Council (ARC) through a DiscoveryProject grant (DP0343994).

\section{References}

Ackoff RL (1967) Management Misinformation Systems. Management Science 14(4): B147-B156.

Anstey K (1999) Understanding and Assessing Cognitive Abilities (Draft paper).

Cognitive Abilities, Surry Hills: Lewis Cadman Consulting.

Barber BM and Odean T (2000) Trading is Hazardous to Your Wealth: The Common

Stock Investment Performance of Individual Investors. Journal of Finance 55: 773-806.

Barber BM and Odean T (2001) Boys will be Boys: Gender, Overconfidence, and

Common Stock Investment. Quarterly Journal of Economics 116: 261-292.

Barber BM and Odean T (2002) Online Investors: Do the Slow Die First?. The Review of Financial Studies 15(2): 455-487.

Ben Zur H and Breznitz SJ (1981) The effect of time pressure on risky choice behaviour. Acta Psychologica 47(2): 89-104.

Benbasat I and Dexter AS (1985) An Experimental Evaluation of Graphical and ColorEnhanced Information Presentation FT. Management Science 31(11): 1348-1364. 
Cassidy R (1967) Auctions and auctioneering. University of California Press.

Cattell RB (1941) Some theoretical issues in adult intelligence testing. Psychological Bulletin 38: 592.

Cattell RB (1971) Abilities: Their structure, growth and action. Boston: HoughtonMifflin.

Chervany NL and Dickson GW (1974) An Experimental Evaluation of Information Overload in a Production Environment. Management Science 20(10): 1335-1344.

Davis DD and Holt CA (1993) Experimental economics. Princeton University Press. Fama E (1970) Efficient Capital Markets: A Review of Theory and Empirical Work. Journal of Finance 25(2): 383-417.

Faul F, Erdfelder E, Lang A-G and Buchner A (2007) G*Power 3: A flexible statistical power analysis program for the social, behavioral, and biomedical sciences. Behavior Research Methods 39: 175-191.

Forsythe R, Palfrey TR and Plott CR (1982) Asset valuation in an experimental market. Econometrica 50: 537-567.

Gode DK and Sunder S (1993), Allocative Efficiency of Markets with Zero-Ability Traders: Market as a Partial Substitute for Individual Rationality. Journal of Political Economy 101(11): 119-137.

Gottfredson LS (1997) Why g matters: The complexity of everyday life. Ability 24: 79132.

Hogarth R (1987) Judgement and choice. Chichester, UK, Wiley.

Horn JL (1982) The theory of fluid and crystallized ability in relationship to concepts of cognitive psychology and ageing in adulthood. In: Craik FIM and Trehub S (eds) Aging and Cognitive Processes. New York: Plenum, 201-238. 
Horn JL (1985) Remodeling old models of ability. In: Wolman BB (ed) Handbook of ability: theories, measurement and applications. New York: John Wiley.

Horn JL (1987) A context for understanding information processing studies of human abilities. In: Vernon PA (ed) Speed of information processing and ability. Norwood, NJ: Ablex, 201-238.

Horn JL (1994) Theory of fluid and crystallized intelligence. In: Sternberg RJ (ed) Encyclopedia of human intelligence. New York: Macmillan, 443-451.

Kagel J and Roth AE (1995) Handbook of experimental economics. Princeton University Press.

Kahneman D (2003) A perspective on judgment and choice: Mapping bounded rationality. American Psychologist 58: 697-720.

Kaplan MF, Wanshula LT and Zanna MP (1993) Time pressure and information integration in social judgement. In: Svenson $\mathrm{O}$ and Maule AJ (eds) Time pressure and stress in human judgement and decision making. New York: Plenum Publishing.

Kerstholt JH (1994) The effect of time pressure on decision-making behaviour in a dynamic task environment. Acta Psychologica 86: 89-104.

Kolz AR, McFarland LA and Silverman SB (1998) Cognitive ability and job experience as predictors of work performance. The Journal of Psychology 132: 539-548.

O’Brien J and Srivastava S (1991) Dynamic Stock Markets With Multiple Assets: An Experimental Analysis. Journal of Finance 46: 811-1838.

Odean T (1999) Do Investors Trade Too Much?. American Economic Review 89: 12791298.

Ordonez L and Benson L (1997) Decisions under time pressure: how time constraint affects risky decision making. Organizational Behavior and Human Decision Processes 71(2): 121-140. 
Payne JW, Bettman JR and Johnson EJ (1993) The adaptive decision maker. New York: Cambridge University Press.

Payne JW, Bettman JR, Johnson EJ and Luce MF (1995) An information processing perspective on choice. In: Busemeyer JR, Hastie R and Medlin D (eds) Decision Making From the Perspective of Cognitive Psychology. Academic Press, 137-175.

Peters LH and O’Conner EJ (1980) Situational Constraints and Work Outcomes: The Influences of a Frequently Overlooked Construct. Academy of Management Journal 5: 391397.

Peters LH, O’Conner EJ, Pooyon A and Quick JC (1984) The Relationship between Time Pressure and Performance: A Field Test of Parkinson's Law. Journal of Occupational Behaviour 5: 293-299.

Plott CR and Sunder S (1982) Efficiency of Experimental Security Markets with Insider Information: An Application of Rational-Expectations Models. Journal of Political Economy 90: 663-698.

Plott CR and Sunder S (1988) Rational Expectations and the Aggregation of Diverse Information in Laboratory Security Markets. Econometrica 56: 1085-1118.

Remus W (1984) An Empirical Investigation of the Impact of Graphical and Tabular Data Presentations on Decision Making. Management Science 30(5): 533-542.

Richardson AP, Gregor S and Heaney RA (2004) Online share trading, time constraints and decision making. In: Proceedings of the Eighth Pacific Asia Conference on Information Systems (PACIS 2004).

Rothstein HG (1986) The effects of time pressure on judgement in multiple cue probability learning. Organizational Behaviour and Human Decision Processes 37: 83-89.

Sackett PR, Gruys ML and Ellingson JE (1998) Ability-personality interactions when predicting work performance. Journal of Applied Psychology 83: 545-536. 
Salthouse TA (1985) A theory of cognitive aging. Amsterdam: North Holland.

Sharda R, Barr S and McDonnell J (1988) Decision Support Systems Effectiveness: A Review and an Empirical Test. Management Science 34: 139-159.

Shefrin H (2000) Beyond greed and fear: Understanding behavioral finance and the psychology of investing. Harvard Business School Press.

Simon H (1957) A Behavioral Model of Rational Choice. In: Models of Man, Social and Rational: Mathematical Essays on Rational Human Behavior in a Social Setting. New York: Wiley.

Smith V (1962) An Experimental Study of Competitive Market Behavior. Journal of Political Economy 70: 111-137.

Svenson O and Maule AJ (1993) Theoretical and empirical approaches to behavioural decision making. In: Svenson O and Maule AJ (eds) Time pressure and stress in human judgement and decision making. New York: Plenum Publishing.

Tabachnick BG and Fidell LS (2001) Using multivariate statistics, Harper Collins College Publishers.

Turban E and Aronson JE (2001) Decision support systems and intelligent systems 6th ed. New Jersey: Prentice Hall.

Wallsten TS and Barton C (1982) Processing probabilistic multidimensional information for decisions. Journal of Experimental Psychology: Learning, Memory and Cognition 8: 361384.

Wright P (1974) The harassed decision maker: Time pressure, distractions, and the use of evidence. Journal of Applied Psychology 59(5): 555-561.

Wu JH and Yuan Y (2003) Improving searching and reading performance: the effect of highlighting and text color coding. Information \& Management 40(7): 617-637. 
Wurman PR, Walsh WE and Wellman MP (1998) Flexible double auctions for electronic commerce: theory and implementation. Decision Support Systems 24(1): 17-27.

Zakay D and Wooler S (1984) Time pressure, training and decision effectiveness. Ergonomics 27(3): 273-284. 